Article

\title{
Antidepressant-Like Effects of Ethanol Extract of Ziziphus jujuba Mill Seeds in Mice
}

\author{
Jong Min Oh ${ }^{1}$, Moongi Ji ${ }^{1}$, Mi-Jin Lee ${ }^{2}$, Geum Seok Jeong ${ }^{1}$, Man-Jeong Paik ${ }^{1}$, Hoon Kim ${ }^{1, * \mathbb{D}}$ \\ and Joo-Won Suh ${ }^{2, *}$ \\ 1 Department of Pharmacy, and Research Institute of Life Pharmaceutical Sciences, Sunchon National \\ University, Suncheon 57922, Korea; 1205027@s.scnu.ac.kr (J.M.O); 1195034@s.scnu.ac.kr (M.J.); \\ 1200058@s.scnu.ac.kr (G.S.J.); paik815@scnu.ac.kr (M.-J.P.) \\ 2 Center for Nutraceutical and Pharmaceutical Materials, Myongji University, Yongin 17058, Korea; \\ mjlee@mju.ac.kr \\ * Correspondence: hoon@sunchon.ac.kr (H.K.); jwsuh@mju.ac.kr (J.-W.S.)
}

Received: 6 October 2020; Accepted: 19 October 2020; Published: 21 October 2020

\begin{abstract}
The antidepressant-like activity of ethanol extract of Ziziphus jujuba Mill var. spinosa seeds (Semen Ziziphi Spinosae, SZS) was investigated by behavioral tests, such as a forced swimming test (FST), a tail-suspension test (TST), and an open field test (OFT), using mice exposed to chronic unpredictable mild stress (CUMS). In the TST, immobility times of the extract-treated groups E100 and E300 (CUMS + 100 and $300 \mathrm{mg} / \mathrm{kg}$ extract, respectively) were significantly decreased in a dose-dependent manner compared with the negative control (CUMS; $p<0.01$, though those of E100 and E300 were higher than those of the positive control (CUMS $+15 \mathrm{mg} / \mathrm{kg}$ fluoxetine). In the FST, immobility times of E100 and E300 were decreased compared to the normal control. In the OFT, total and zone distances of E100 and E300 were significantly higher than those of negative controls $(p<0.01)$ with a dose dependency. In liquid chromatography-tandem mass spectrometry (LC-MS/MS) analysis after behavioral tests, norepinephrine (NE) and 5-hydroxytryptamine (5-HT) levels in the hippocampus tissues of E100 and E300 were significantly higher than those of negative controls. Brain-derived neurotrophic factor (BDNF) levels in the hippocampus tissues of E100 and E300 were higher than those of negative controls. From these results, the SZS ethanol extract exhibited significant antidepressant-like effects via immobility decrease, distance increase, hippocampal NE and 5-HT increase, and BDNF expression. These results suggest that the extract could be a potential antidepressant agent.
\end{abstract}

Keywords: Ziziphus jujuba Mill var. spinosa; ethanol extract; antidepressant-like effect; CUMS; FST; TST; OFT; LC-MS/MS; BDNF

\section{Introduction}

Depression is expanding to become a global health problem and its exact cause has not been identified, although much has been reported on its etiology [1,2]. Several drugs have been used for the treatment of depression, such as monoamine oxidase inhibitors (MAOIs), tricyclic antidepressants (TCAs), selective serotonin reuptake inhibitors (SSRIs), serotonin-norepinephrine reuptake inhibitors (SNRIs), norepinephrine-dopamine reuptake inhibitors (NDRIs), and N-methyl-D-aspartate receptor (NMDAR) antagonists [3,4]. These inhibitors increase monoamine neurotransmitters such as norepinephrine (NE), 5-hydroxytryptamine (5-HT, serotonin), and dopamine (DA). Among the MAOIs, moclobemide and toloxatone (selective MAO-A) and selegiline (selective MAO-B) have been used in the market as antidepressants. On the other hand, depression treatments such as 
antidepressants were found to increase the expression of brain-derived neurotrophic factor (BDNF) in the brain [5].

Semen Ziziphi Spinosae (SZS), the dried seeds of Ziziphus jujuba Mill var. spinosa (Bunge) Hu ex H.F. Chou, has traditionally been used for the treatment of insomnia and anxiety in oriental countries such as Korea and China [6,7]. SZS has been found to have neuroprotective [6], sedative and hypnotic [8], hepaprotective [9], wound-healing [10], anti-aging [11], and cognitive [12,13] effects, as well as antioxidant [14], anti-inflammatory [15], anti-hypertensive [16,17], anti-bacterial [18], cytoprotective (antioxidant) [19], anti-genotoxic [20], hematopoietic [21], anti-cancer [22], immunological and anti-complementary [23], synaptic transmission [24], and anti-anxiety [25] activities.

During the on-going study to search for antidepressant materials, we selected SZS as an experiment source based on its diverse biological activities and possible activities on the central nervous system (CNS) as described above. In this study, the antidepressant activity of ethanol extract of Z. jujuba Mill var. spinosa seeds was investigated using a tail-suspension test (TST), a forced swimming test (FST), and an open field test (OFT) with mice. In addition, MAO-A, MAO-B, acetylcholinesterase (AChE), and butyrylcholinesterase (BChE) activities in the brain were assayed, levels of the monoamine neurotransmitters were analyzed by liquid chromatography-tandem mass spectrometry (LC-MS/MS), and the level of BDNF was analyzed by Western blotting.

\section{Materials and Methods}

\subsection{Plant Material and Extract Preparation}

SZS (permitted by Korea Food and Drug Administration, KFDA), the dried seeds of Z. jujuba Mill var. spinosa (Bunge) Hu ex H.F. Chou, derived from the Rhamnaceae species, was purchased from a local market (http://nonglim.co.kr/). The SZS was immersed in 4 volumes of $70 \%$ ethanol and boiled for $6 \mathrm{~h}$ at $85^{\circ} \mathrm{C}$. This was done twice. The solution was then filtered, concentrated up to 20 Brix at $60{ }^{\circ} \mathrm{C}$ by depressurized evaporation, and stored at $4{ }^{\circ} \mathrm{C}$ before use.

\subsection{Chemicals and Enzymes}

Fluoxetine, dimethyl sulfoxide (DMSO), methanol (MeOH), ethyl acetate (EA), acetic acid, chloroform, toluene, dioxane, dichloromethylene (DCM), NE, epinephrine (EP), DA, 5-HT, 3,4-dihydroxyphenylacetic acid (DOPAC), 5-hydroxyindoleacetic acid (5-HIAA), 3,4-dimethoxybenzoic acid (DMBA), $\gamma$-amino butyric acid (GABA), glutamic acid, kynuramine, benzylamine, acetylthiocholine iodide (ACTI), butyrylthiocholine iodide (BCTI), and 5,5'-dithiobis(2-nitrobenzoic acid) (DTNB) were purchased from Sigma-Aldrich (St. Louis, MO, USA). Spinosin was purchased from ChemFaces (CFN99600, Wuhan, China). High-performance liquid chromatography (HPLC)-grade water (DW) and acetonitrile (ACN) were purchased from J.T. Baker Inc. (Phillipsburg, NJ, USA). LC-MS-grade formic acid (FA) was purchased from Thermo Fisher Scientific Inc. (Rockford, IL, USA). Recombinant human MAO-A and MAO-B, $\mathrm{AChE}$ from Electrophorus electricus, and $\mathrm{BChE}$ from equine serum were purchased from Sigma-Aldrich.

\subsection{Animals and Administration}

Naïve male ICR mice (six weeks old, $30 \pm 1 \mathrm{~g}$ ) were obtained from RaonBio Inc. Yongin, Republic of Korea and maintained under standard conditions as described previously [26]. Experiments for animals were carried out according to protocols approved by Sunchon National University Institutional Animal Care and Use Committee (SCNU IACUC, permit number: SCNU IACUC-2020-07). On arrival, animals were allowed to acclimatize for 7 days and were supplied with standard chow and water ad libitum. Mice were then randomly divided into 5 groups $(n=7 /$ group $)$ and treated with chronic unpredictable mild stress (CUMS), except for the normal control, based on the methods described by Szewczyk et al. [27], with modifications. The groups were: normal control (C), administered phosphate-buffered saline (PBS) solution $(0.9 \% \mathrm{NaCl})$; negative control $(\mathrm{N})$ with CUMS; positive 
control (P), administered fluoxetine $(15 \mathrm{mg} / \mathrm{kg})$ with CUMS; and 2 treatment groups administered extract of SZS (E100 and E300 with 100 and $300 \mathrm{mg} / \mathrm{kg}$, respectively) with CUMS. The materials were dissolved in PBS solution. The saline and fluoxetine were administered by intraperitoneal injection (i.p.) at a volume of $0.3 \mathrm{~mL}$ and the SZS extract was administered orally (p.o.). CUMS proceeded randomly in a total of 8 cases, by picking out a sheet on which a case number is written. The methods were applied as follows: (1) exposed to an empty cage for $9 \mathrm{~h}$; (2) nipping of the tail for 2 min every $3 \mathrm{~h}$, 3 times; (3) food removed for $9 \mathrm{~h}$; (4) water removed for $9 \mathrm{~h}$; (5), fed with wet feed; (6) left alone in 1 cage for $9 \mathrm{~h}$; (7) lighting kept on for $24 \mathrm{~h}$; (8) kept in darkness for $24 \mathrm{~h}$. The same CUMS methods were not applied. Behavioral tests were performed 30 min later.

\subsection{Behavioral Experiments}

Antidepressant-like activity was evaluated using the FST, TST, and OFT. The FST was performed based on the method of Porsolt et al. [28] with slight modifications, as described previously [26]. Immobility times were recorded over the last 4 min of a 6 min test, using an open cylinder $(20 \mathrm{~cm} \times 30 \mathrm{~cm})$ filled with water to a height of $16 \mathrm{~cm}$. The TST was carried out using Steru et al.'s [29] method with slight modifications [26]. A mouse was suspended by taping the tail at $2 \mathrm{~cm}$ from the tip in a Plexiglas box $(25 \mathrm{~cm} \times 25 \mathrm{~cm} \times 50 \mathrm{~cm})$. Immobility times were recorded over the last $4 \mathrm{~min}$ of a 6 min experiment under dark and quiet conditions. The OFT was conducted on a square platform $(30 \mathrm{~cm} \times 30 \mathrm{~cm})$, of which the center zone was $10 \mathrm{~cm} \times 10 \mathrm{~cm}$ and was divided into 9 equal squares. A mouse was placed in the center of the platform, and three parameters were checked to evaluate depressive symptoms for $8 \mathrm{~min}$ : time or distance in the center zone, and total distance on the platform [30].

The tests were recorded on videotape, and data were analyzed using EthoVision XT Base version 14 (Noldus, Wageningen, The Netherlands).

\subsection{Tissue Preparations}

After the FST, TST, and OFT were finished, mice were sacrificed by cervical dislocation. Whole brains were then collected and the hippocampi were dissected. The tissue was washed with ice-cold Dulbecco's phosphate buffered saline (DPBS) and stored at $-80^{\circ} \mathrm{C}$ until used. For LC-MS/MS, the part was homogenized in $0.1 \%$ FA $(400 \mathrm{mg} / \mathrm{mL})$ using an ultrasonicator (VCX-600, Sonics \& Materials, Danbury, CT, USA) and the supernatant was collected by centrifugation at $12,300 \times g$ for $15 \mathrm{~min}$ at $4{ }^{\circ} \mathrm{C}$ [26]. For Western blot, the tissue was dissolved in RIPA lysis buffer $(50 \mathrm{mM}$ Tris- $\mathrm{HCl}, 150 \mathrm{mM} \mathrm{NaCl}, 1.0 \%(v / v) \mathrm{NP}-40,0.5 \%(w / v)$ sodium deoxycholate, $0.01 \%(w / v)$ sodium azide, pH 7.4) containing Halt ${ }^{\mathrm{TM}}$ Protease and Phosphatase Inhibitor Cocktail (Thermo Fisher Scientific Inc.). The protein concentration of each sample was adjusted to be identical using a Bradford protein assay kit (Bio-Rad Laboratories, Hercules, CA, USA).

\subsection{Analysis of MAO-A, MAO-B, AChE, and BChE Activities}

MAO-A and MAO-B activities of the extract and spinosin were continuously assayed as described previously [31] using kynuramine $(0.06 \mathrm{mM})$ and benzylamine $(0.3 \mathrm{mM})$ as substrates, respectively. $\mathrm{AChE}$ and $\mathrm{BChE}$ activities were measured as described previously [32] using the presence of $0.5 \mathrm{mM}$ ACTI and BTCI as substrates, respectively, by adding $0.5 \mathrm{mM}$ DTNB as a color-developing agent. For the assays of tissues, $40 \mu \mathrm{g}$ of proteins were used in $0.5 \mathrm{~mL}$ reaction mixtures.

\subsection{Analysis of Neurotransmitter Amines and Metabolites in Hippocampus Tissues by LC-MS/MS}

Neurotransmitter amines and metabolites were analyzed as described previously [26], with slight modifications. Briefly, the concentrations of the 8 standards (NE, EP, DA, 5-HT, 5-HIAA, DOPAC, GABA, and glutamic acid) and DMBA as an internal standard were 0.004 and $0.1 \mathrm{mg} / \mathrm{mL}$, respectively, in DW containing $0.1 \%$ FA $(v / v)$. For deproteinization, samples $(150 \mu \mathrm{L})$ were mixed with $0.1 \mathrm{mg} / \mathrm{mL}$ of DMBA $(20 \mu \mathrm{L})$ and ACN containing $1 \%$ FA $(330 \mu \mathrm{L})$. After centrifugation, samples $(10 \mu \mathrm{L})$ were analyzed by LC-MS/MS (LCMS-8050, Shimadzu Corp., Kyoto, Japan) using a Kinetex $\mathrm{C}_{18}$ column 
( $250 \mathrm{~mm} \times 4.6 \mathrm{~mm}, 5 \mu \mathrm{m}, 100 \AA$ ) of Phenomenex (Torrance, CA, USA) at a flow rate of $0.30 \mathrm{~mL} / \mathrm{min}$ with a gradient of phase A (DW containing $0.1 \% \mathrm{FA}$ ) and B (ACN containing $0.1 \% \mathrm{FA}$ ): $0 \%$ of $\mathrm{B}$ for $6 \mathrm{~min}, 100 \%$ of $\mathrm{B}$ from 6 to $15 \mathrm{~min}$, and $100 \%$ of $\mathrm{B}$ for $23 \mathrm{~min}$ followed by a return to $0 \%$ of $\mathrm{B}$ and a $12 \mathrm{~min}$ re-equilibration period. MS/MS was performed in electrospray ionization (ESI) mode.

\subsection{Western Blot}

Proteins of the prepared samples were separated using 11\% SDS-PAGE gels, and were transferred to nitrocellulose membranes (Thermo Fisher Scientific Inc.) according to the methods described previously [33], with modifications. The membranes were blocked in Tris-buffered saline (TBS) containing $5 \%$ bovine serum albumin (BSA) for $1 \mathrm{~h}$ at room temperature, and incubated at $4^{\circ}$ overnight with BDNF recombinant rabbit monoclonal antibody and $\beta$-actin polyclonal antibody (Thermo Fisher Scientific Inc., Waltham, MA, USA, 1:2000). The membranes were washed with TBS containing $20 \%$ Tween 20 (TBST) and incubated with horseradish-peroxidase-conjugated goat anti-rabbit IgG $(\mathrm{H}+\mathrm{L})$ secondary antibody (Thermo Fisher Scientific Inc., Waltham, MA, USA, 1:10000) for $1 \mathrm{~h}$ at room temperature. The membranes were then washed with TBST and developed with an enhanced chemiluminescence kit (Thermo Fisher Scientific Inc., Waltham, MA, USA). The protein bands were detected using MicroChemi 4.2 (DNR Bio-Imaging Systems Ltd., Neve Yamin, Israel). The BDNF was normalized to the $\beta$-actin band.

\subsection{Statistical Analysis}

The immobility times (FST and TST) and distances (OFT) were analyzed statistically. The levels of NE, EP, 5-HT, DA, DOPAC, 5-HIAA, GABA, and glutamic acid in mouse hippocampus tissues were quantitatively determined based on calibration curves. Levels in mouse hippocampus tissues were then normalized versus corresponding control mean values and plotted as bar graphs using GraphPad PRISM 7.0a (GraphPad, San Diego, CA, USA). The Mann-Whitney test was used to determine the significances of the differences between metabolites levels in the $\mathrm{C}$ and $\mathrm{N}$ controls, and between the $\mathrm{N}$ control and each of the three groups (i.e., $\mathrm{P}$ control, or the 2 extract-treated groups) using IBM SPSS Statistics 20 (IBM Corporation, Armonk, NY, USA). The Kruskal-Wallis test was also used to determine the significances of the differences among the four groups (i.e., $\mathrm{N}$ and $\mathrm{P}$ controls, and the 2 extract-treated groups).

\section{Results and Discussion}

\subsection{SZS Extract and Inhibitory Activities against MAO-A, MAO-B, AChE and BChE}

The SZS was extracted with the treatment of $70 \%$ ethanol and boiling. The yield was found to be $5.1 \%(w / w)$. Inhibitory activities of the extract against MAO-A, MAO-B, AChE, and BChE, relating to neurologic pathways, were evaluated along with a flavone C-glycoside spinosin, which is a major constituent of SZS. The SZS extract showed $67.9 \%$ and $58.4 \%$ of the residual activities against MAO-B and AChE, respectively, at $50 \mu \mathrm{g} / \mathrm{mL}$ (Table 1). The inhibitory activities against MAO-A and BChE were not effective. Spinosin exhibited moderate inhibitory activities against $\mathrm{MAO}-\mathrm{B}$ and $\mathrm{AChE}$, with $\mathrm{IC}_{50}$ values of 63.3 and $39.8 \mu \mathrm{M}$, respectively. However, the values were higher than those of reference inhibitor compounds. 
Table 1. Inhibitions of recombinant human monoamine oxidase (MAO) enzymes, acetylcholinesterase (AChE), and butyrylcholinesterase (BChE) by Semen Ziziphi Spinosae (SZS) extract and spinosin.

\begin{tabular}{ccccccccc}
\hline \multirow{2}{*}{ Compounds } & \multicolumn{3}{c}{ Residual Activity (\%) at $\mathbf{4 0} \boldsymbol{\mu M}$} & \multicolumn{4}{c}{ IC $_{\mathbf{5 0}}(\boldsymbol{\mu M})$} \\
\cline { 2 - 9 } & MAO-A & MAO-B & AChE & BChE & MAO-A & MAO-B & AChE & BChE \\
\hline SZS a & $79.2 \pm 2.53$ & $67.9 \pm 1.81$ & $58.4 \pm 5.26$ & $79.5 \pm 0.71$ & - & - & - & - \\
Spinosin & $86.9 \pm 0.00$ & $67.9 \pm 3.02$ & $50.2 \pm 1.05$ & $83.5 \pm 7.78$ & $>80$ & $63.3 \pm 0.075$ & $39.8 \pm 0.40$ & $>80$ \\
Toloxatone & & & & & $1.08 \pm 0.025$ & - & - & - \\
Lazabemide & & & & - & $0.063 \pm 0.015$ & - & - \\
Tacrine & & & & & - & - & $0.27 \pm 0.019$ & $0.014 \pm 0.0043$ \\
\hline
\end{tabular}

Results are expressed as means \pm standard errors of triplicate experiments. Values for reference compounds were determined after preincubation for 30 min with enzymes. ${ }^{a}$ Residual activities at $50 \mu \mathrm{g} / \mathrm{mL}$.

\subsection{Animal Experiment Plan}

After acclimatization of the animals for 1 week, those under CUMS were treated to the end of the experiments for 4 weeks and 3 days, and the drug and the extract were administered 2 days after starting the CUMS (Figure 1). Animal behavioral tests (FST, TST, and OFT) were conducted for 3 days starting on the first day of the fifth week in order. The next day, the mice were sacrificed and hippocampus tissues were isolated.

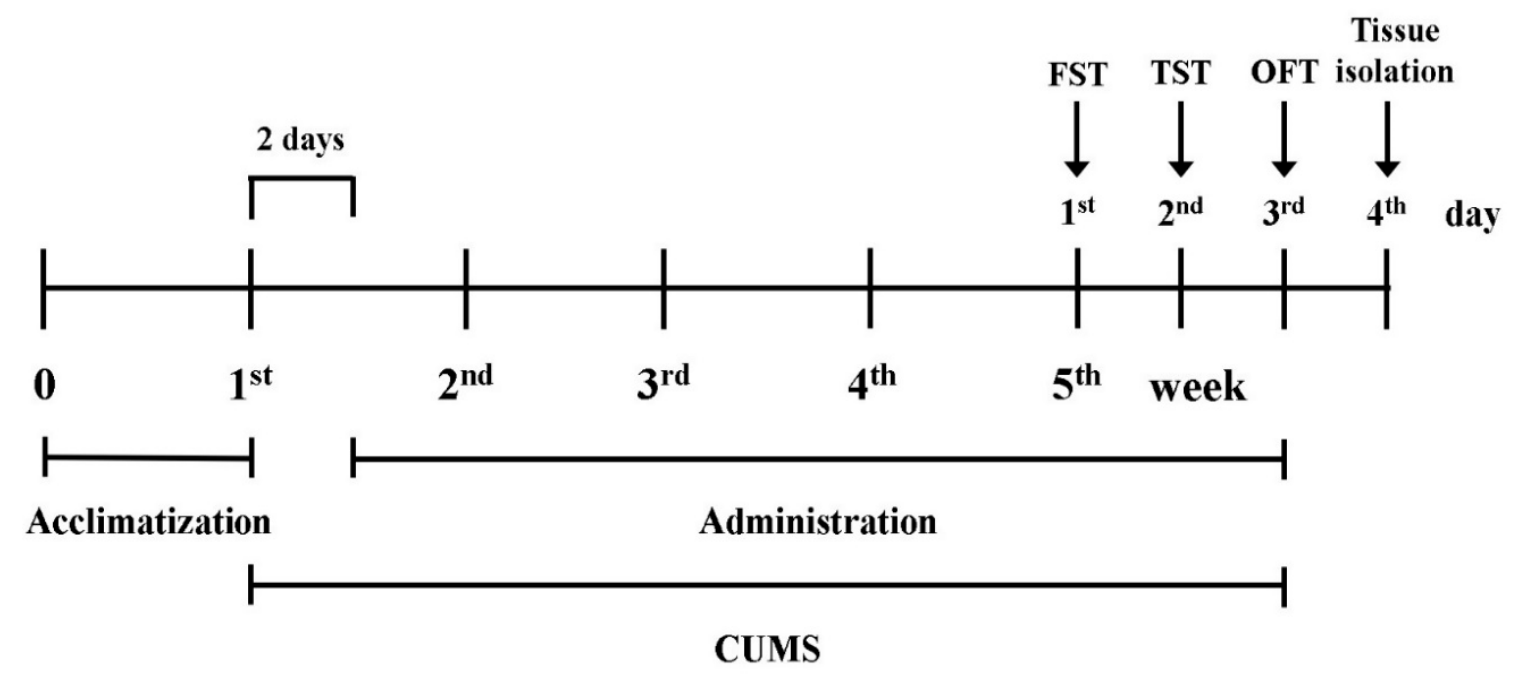

Figure 1. The overall procedure of animal behavioral experiments. FST: forced swimming test; TST: tail-suspension test; OFT: open field test; CUMS: chronic unpredictable mild stress.

\subsection{Behavioral Tests}

In the FST, immobility times of the SZS-extract-treated groups, E100 and E300, were decreased compared to $\mathrm{C}$, but not significantly, while those of $\mathrm{N}$ were significantly increased compared to $\mathrm{C}$ $(p<0.05)$ and those of $\mathrm{P}$ were significantly decreased compared to $\mathrm{N}(p<0.01$; Figure 2$)$. In the TST, immobility times of E100 and E300 were significantly decreased compared to N $(p<0.01)$, with a dose dependency (Figure 2). Moreover, the immobility time of $\mathrm{N}$ was significantly increased compared to $\mathrm{C}$ $(p<0.05)$, and that of $\mathrm{P}$ was significantly decreased compared to $\mathrm{N}(p<0.01)$. The results of immobility times between N, P, E100, and E300 in both tests were statistically significant $(p<0.001)$.

In the OFT, the total distances of E100 and E300 were significantly higher than those of $\mathrm{N}(p<0.01)$ with a dose-dependent relationship close to that of $C$, and the results of the distances between $N, P$, E100, and E300 were statistically significantly different $(p<0.001$; Figure 3). Zone distances of E100 and E300 were higher than those of P, with a dose-dependency ( $p<0.01$; Figure 3$)$. However, times in zone of E100 and E300 were ineffective (i.e., lower than those of N) (Figure 3). 


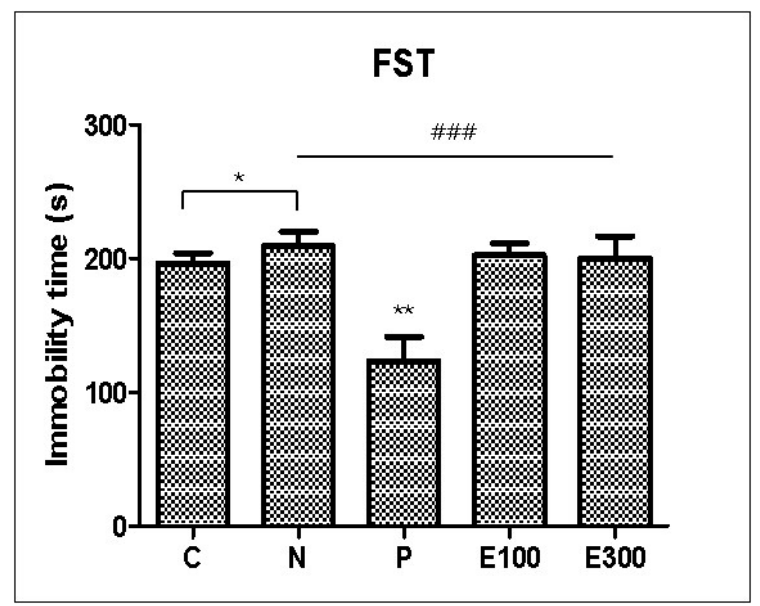

(A)

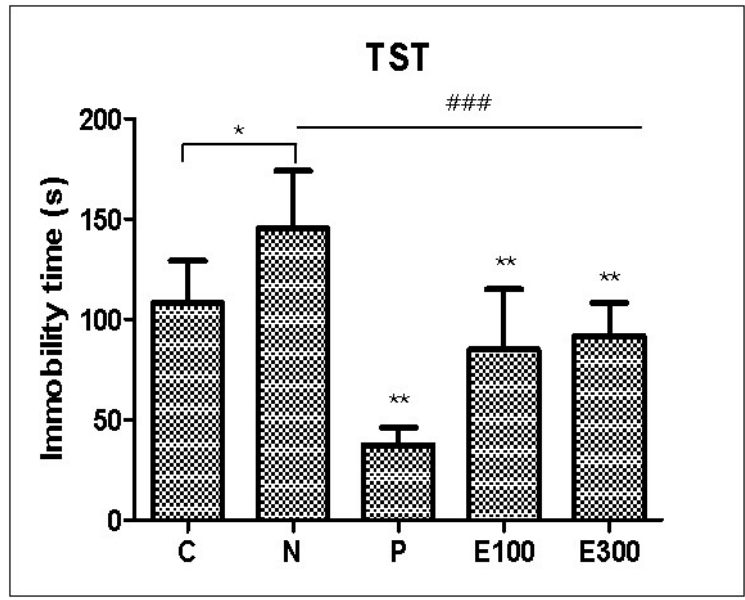

(B)

Figure 2. Behavioral analyses of the forced swimming test (FST) (A) and tail-suspension test (TST) (B) after intraperitoneal injection of fluoxetine and oral administration of the extract into mice $(n=7)$. C: normal control; N: negative control (chronic unpredictable mild stress (CUMS)); P: positive control (CUMS + $15 \mathrm{mg} / \mathrm{kg}$ fluoxetine); E100 and E300: doses of the extract (CUMS + 100 and $300 \mathrm{mg} / \mathrm{kg}$, respectively). \#: Kruskal-Wallis test; *: Mann-Whitney test. \#\#\#: $p<0.001 ;{ }^{*}: p<0.05 ;{ }^{* *}: p<0.01$.

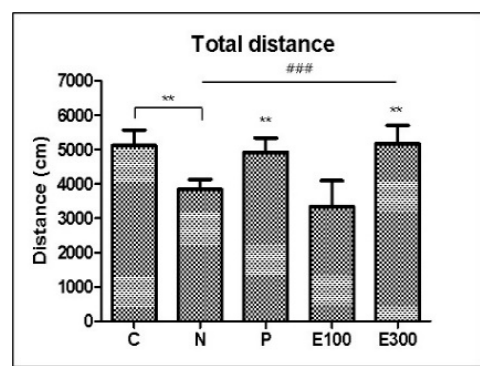

(A)

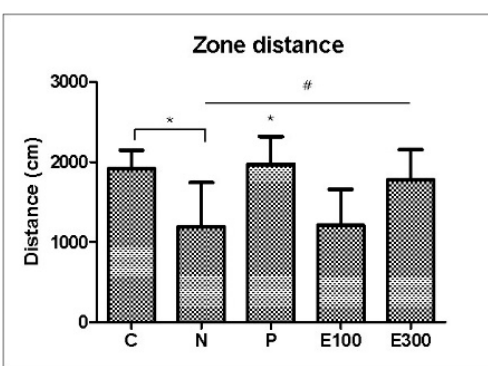

(B)

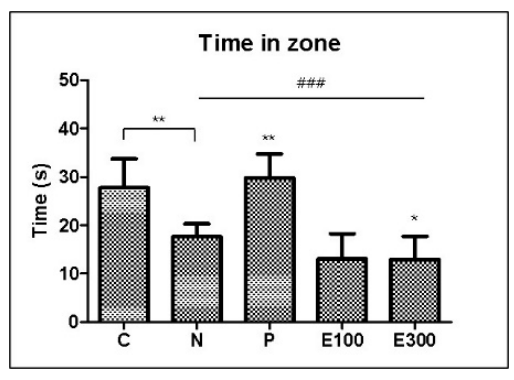

(C)

Figure 3. Behavioral analysis of the open field test (OFT) after intraperitoneal injection of fluoxetine and oral administration of the extract into mice $(n=7)$. (A) Total distance; (B) Zone distance; (C) Time in zone. C: normal control; N: negative control (CUMS); P: positive control (CUMS + $15 \mathrm{mg} / \mathrm{kg}$ fluoxetine); E100 and E300: doses of the extract (CUMS + 100 and $300 \mathrm{mg} / \mathrm{kg}$, respectively). \#: Kruskal-Wallis test;

*: Mann-Whitney test. \#: $p<0.05$; \#\#: $p<0.001$; $: p<0.05 ;{ }^{* *}: p<0.01$.

\subsection{LC-MS/MS Analysis of Neurotransmitter Monoamines and Metabolites}

After the FST, TST, and OFT, the levels of NE, EP, 5-HT, DA, DOPAC, 5-HIAA, GABA, and choline in mouse hippocampus tissues were quantitatively determined based on calibration curves and then normalized. In the hippocampus, five compounds were detected; NE, EP, 5-HT, GABA, and choline levels of E100 and/or E300 were significantly higher than those of $\mathrm{N}$ with dose-dependencies (NE, $p<0.01$; EP, $p<0.05$; 5-HT, $p<0.05$; GABA, $p<0.01$; choline, $p<0.01$; Figure 4). The concentrations of NE, EP, 5-HT, GABA, and choline were $0.16 \pm 0.0021,1.84 \pm 0.25,0.12 \pm 0.0035,542.5 \pm 94.7$, and $178.6 \pm 27.9 \mathrm{ng} / \mathrm{mg}$ protein in control; those in CUMS-treated negative controls were decreased, those in positive controls were increased, and those in E100 and E300 were increased to the positive controls (Table S1). Levels of DA, 5-HIAA, and DOPAC were too low to be detected. 


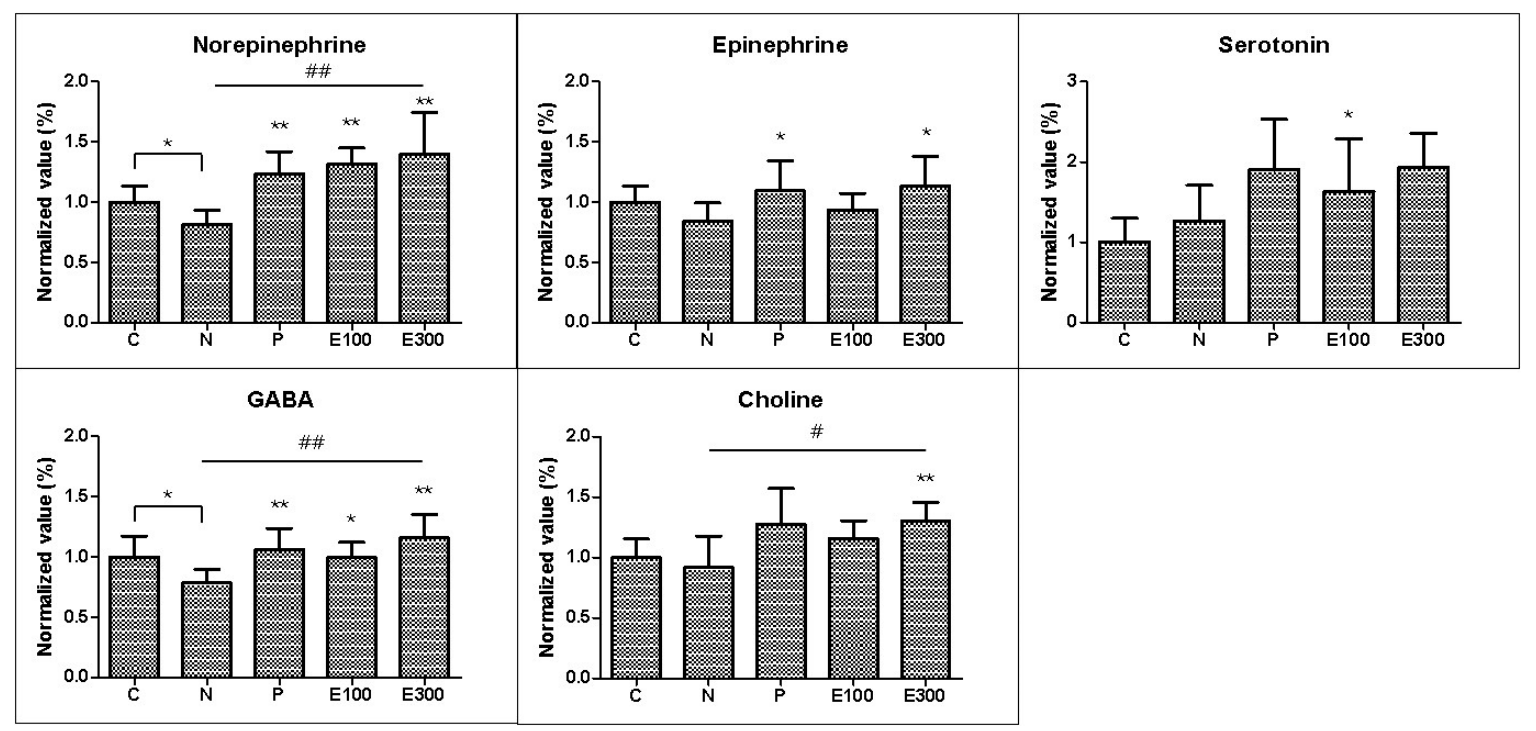

Figure 4. LC-MS/MS analysis of neurotransmitters in the hippocampi of mouse brains after behavioral tests by intraperitoneal injection of fluoxetine and oral administration of the extract into mice $(n=7)$. C: normal control; N: negative control (CUMS); P: positive control (CUMS + $15 \mathrm{mg} / \mathrm{kg}$ fluoxetine); E100 and E300: doses of the extract (CUMS +100 and $300 \mathrm{mg} / \mathrm{kg}$, respectively). GABA: $\gamma$-amino butyric acid. \#: Kruskal-Wallis test; *: Mann-Whitney test. \#: $p<0.05$; \#\#: $p<0.01 ;{ }^{*}: p<0.05 ;{ }^{* *}: p<0.01$.

\subsection{Analysis of MAO-A, MAO-B, AChE, and BChE Activities in Hippocampus Tissues}

MAO-A, MAO-B, AChE, and BChE activities of the hippocampus tissues were assayed. In the hippocampus of E100 and E300, the content of AChE was increased, but with no dose-dependency (Table 2). Other enzyme activities were not significant.

Table 2. MAO-A, MAO-B, AChE, and BChE activities of the hippocampus in normalized values.

\begin{tabular}{ccccc}
\hline \multirow{2}{*}{ Group } & \multicolumn{4}{c}{ Normalized Value $(\boldsymbol{n}=7)$} \\
\cline { 2 - 5 } & MAO-A & MAO-B & AChE & BChE \\
\hline C & $1.00 \pm 0.70$ & $1.00 \pm 0.55$ & $1.00 \pm 0.72$ & $1.00 \pm 1.11$ \\
N & $1.65 \pm 0.97$ & $0.99 \pm 0.48$ & $1.65 \pm 0.78$ & $0.65 \pm 0.26$ \\
P & $1.06 \pm 0.31$ & $1.00 \pm 0.37$ & $2.33 \pm 1.37$ & $0.98 \pm 0.86$ \\
E100 & $1.08 \pm 0.37$ & $0.75 \pm 0.43$ & $1.52 \pm 0.76$ & $0.42 \pm 0.23$ \\
E300 & $1.22 \pm 0.26$ & $0.56 \pm 0.47$ & $0.99 \pm 0.20$ & $0.42 \pm 0.22$ \\
\hline
\end{tabular}

C: normal control; N: negative control (CUMS); P: positive control (CUMS + $15 \mathrm{mg} / \mathrm{kg}$ fluoxetine); E100 and E300: doses of the extract (CUMS +100 and $300 \mathrm{mg} / \mathrm{kg}$, respectively).

\subsection{Western Blot}

Western blot was performed using the same amount of protein. BDNF levels of hippocampus tissues in E100 and E300 were significantly higher than those in the control and in the positive control $(p<0.05$; Figure 5).

SZS has various biological activities, and many studies have reported its neuroprotective [6], sedative and hypnotic [8], and anxiety suppression [25] effects, as well as anti-Alzheimer's disease activities [12,13,34-36]. However, little information is available about the antidepressant activity of SZS. Very recently, Ziziphus mucronata showed an antidepressant effect in chronically stressed rats due to its capacities for antioxidant activity, and probably the modulation of monoamines transmission [37]. Spinosin, a major constituent of SZS, has been reported to have the activities of neurogenesis for cognitive improvement [38-40], sleep reduction for the treatment of insomnia [41], neuroprotection [42], and cardioprotection [43]. However, the antidepressant activity of spinosin was not previously reported. 

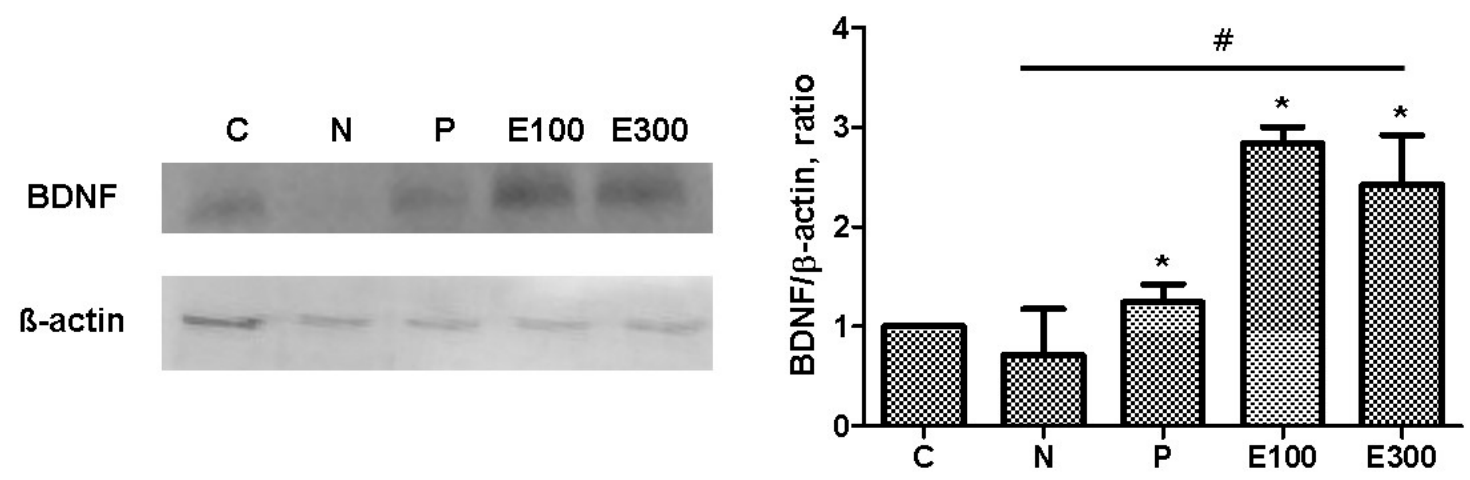

Figure 5. Western blot of brain-derived neurotrophic factor (BDNF) in the hippocampus. C: normal control; N: negative control (CUMS); P: positive control (CUMS + $15 \mathrm{mg} / \mathrm{kg}$ fluoxetine); E100 and E300: doses of the extract (CUMS + 100 and $300 \mathrm{mg} / \mathrm{kg}$, respectively). The intensities of the bands were quantified with a densitometer $(n=3)$. The $\beta$-actin was used to normalize the BDNF. \#: Kruskal-Wallis test; *: Mann-Whitney test. \#: $p<0.05 ;{ }^{*}: p<0.05$.

SZS showed MAO-B and AChE inhibitory activities in vitro; however, MAO-B activity in the hippocampus was low and AChE activity was detected, but differences between the control and dosed groups were not significant. These results suggest that the antidepressant activity of SZS is mediated via pathways other than MAO-B or AChE inhibitions, similar to the results of novel herbal treatment [44].

The CUMS method is widely used to investigate antidepressant activity in animal models [45]. CUMS can induce behavioral changes resembling clinical depression, and these parameters can be reversed or prevented by chronic antidepressant treatment [46]. In addition, the TST, FST, and OFT were performed as behavioral tests to investigate antidepressant effects, as many other studies have reported [47-49]. FST and TST are the two most validated behavioral assays for assessing antidepressant potential [50,51]. To avoid false-positive results, OFT is used to evaluate locomotor activity [30]. In this study, the tests were carried out using CUMS-treated mice. The TST experiments showed significant decreases in immobility times, and the FST experiments also exhibited decreases in immobility times in the SZS-extract-treated groups. In the OFT, total and zone distances were significantly increased with a dose dependency. In addition, neurotransmitter monoamines levels in the hippocampus tissues were significantly increased in the extract-treated groups.

BDNF was expressed as up-regulated by antidepressant treatment $[5,52]$, and also plays an important role in neurogenesis and antidepressant-like behavior [47]. The chronic administration of antidepressant has been found to increase the expression of BDNF in the rodent hippocampus [53]. In this study, the mechanism of SZS for antidepressant effects was investigated via assaying BDNF expression by Western blot and the levels of neurotransmitter monoamines by LC-MS/MS in the hippocampus. In our results, BDNF expression was significantly increased in the dosed groups, similar to other results of around two-to four-fold increases [54-56], and NE and 5-HT levels were increased, similarly to the selective serotonin reuptake inhibitors (SSRIs) [53]. It is suggested that the antidepressant-like activity is mainly dependent on BDNF expression and NE and 5-HT increases in the hippocampus (Figure 6).

From these results, the SZS ethanol extract exhibited significant antidepressant-like effects via immobility decreases in FST and TST, distance increases in OFT, hippocampal NE and 5-HT increases, and BDNF expression increase in the hippocampus. 


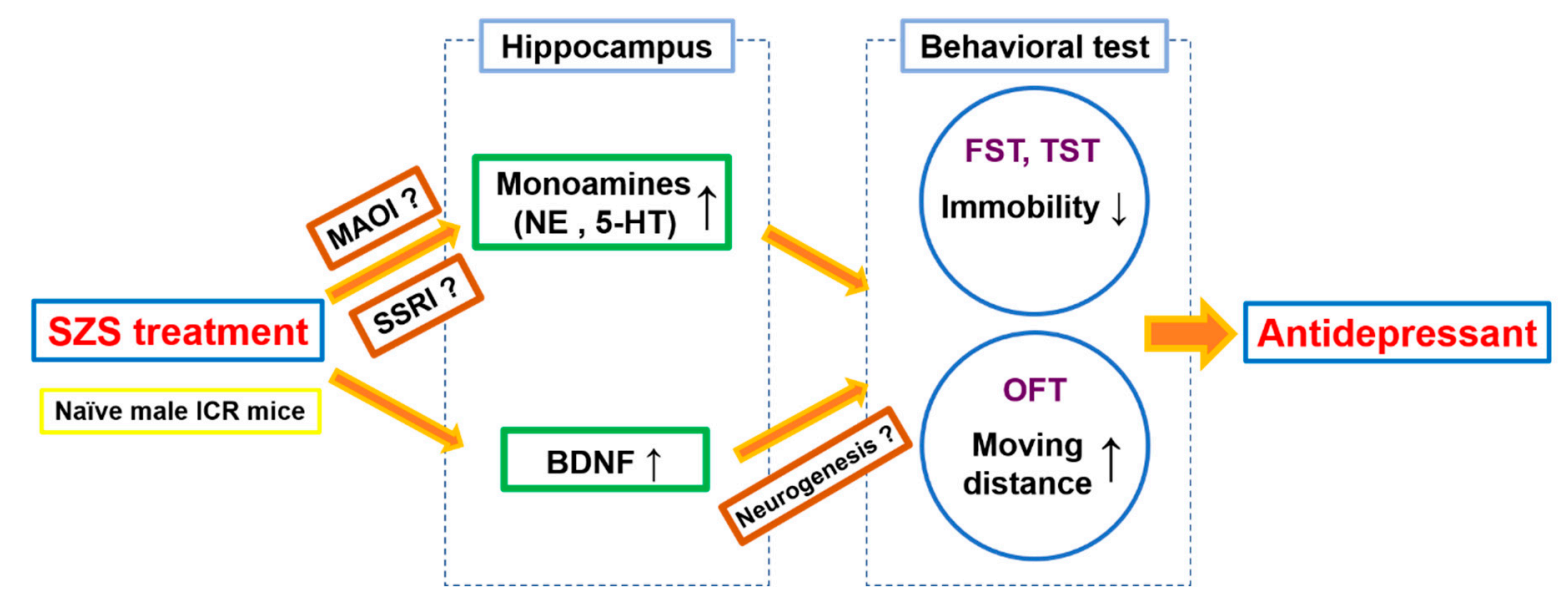

Figure 6. A pictogram illustrating the hypothesized mechanism of action for SZS as an antidepressant. SZS: Semen Ziziphi Spinosae.

\section{Conclusions}

In this study, the antidepressant-like activity of SZS ethanol extract was investigated using mice exposed to CUMS. In the TST, immobility times of the extract-treated groups were significantly decreased compared to the negative control, demonstrating a dose-dependency. In the FST, immobility times of the dosed groups were decreased compared to the normal control. In the OFT, total and zone distances of dosed groups were significantly higher than those of negative controls, with a dose-dependent relationship. After behavioral tests, NE and 5-HT levels in the hippocampus tissues of dosed groups were significantly higher than those of negative controls. BDNF levels in the hippocampus tissues of dosed groups were higher than those of negative controls. These results suggest that the SZS extract could be a potential antidepressant agent.

Supplementary Materials: The following is available online at http://www.mdpi.com/xxx/s1. Table S1: Levels of neurotransmitter amines, GABA, and choline in mouse hippocampus tissues after experiments administered by SZS $(n=7)$.

Author Contributions: Conceptualization: H.K., J.-W.S.; extraction: M.-J.L.; biological activity: J.M.O.; behavioral tests: J.M.O., G.S.J.; monoamine analysis: M.J., M.-J.P.; data analysis: J.M.O.; original draft writing: J.M.O., M.-J.L.; review and editing: M.-J.P., H.K., and J.-W.S.; supervision: H.K.; funding acquisition: H.K., J.-W.S. All authors have read and agreed to the published version of the manuscript.

Funding: This study was supported by the Cooperative Research Program for Agriculture Science and Technology Development (\#PJ01319104) of the Rural Development Administration, Republic of Korea.

Conflicts of Interest: The authors have no conflicts of interest to declare.

\section{References}

1. Duman, R.S.; Voleti, B. Signaling pathways underlying the pathophysiology and treatment of depression: Novel mechanisms for rapid-acting agents. Trends Neurosci. 2012, 35, 47-56. [CrossRef] [PubMed]

2. Cui, R. Editorial: A systematic review of depression. Curr. Neuropharmacol. 2015, 13, 480. [CrossRef]

3. Ramachandraih, C.T.; Subramanyam, N.; Bar, K.J.; Baker, G.; Yeragani, V.K. Antidepressants: From MAOIs to SSRIs and more. Indian J. Psychiatry 2011, 53, 180-182.

4. Fitzgerald, P.J.; Watson, B.O. In vivo electrophysiological recordings of the effects of antidepressant drugs. Exp. Brain Res. 2019, 237, 1593-1614. [CrossRef]

5. Shimizu, E.; Hashimoto, K.; Okamura, N.; Koike, K.; Komatsu, N.; Kumakiri, C.; Nakazato, M.; Watanabe, H.; Shinoda, N.; Okada, S.; et al. Alterations of serum levels of brain-derived neurotrophic factor (BDNF) in depressed patients with or without antidepressants. Biol. Psychiatry 2003, 54, 70-75. [CrossRef]

6. Park, J.H.; Lee, H.J.; Koh, S.B.; Ban, J.Y.; Seong, Y.H. Protection of NMDA-induced neuronal cell damage by methanol extract of Zizyphi spinosi semen in cultured rat cerebellar granule cells. J. Ethnopharmacol. 2004, 95, 39-45. [CrossRef] [PubMed] 
7. Shergis, J.L.; Ni, X.; Sarris, J.; Zhang, A.L.; Guo, X.; Xue, C.C.; Lu, C.; Hugel, H. Ziziphus spinosa seeds for insomnia: A review of chemistry and psychopharmacology. Phytomedicine 2017, 34, 38-43. [CrossRef] [PubMed]

8. Jiang, J.G.; Huang, X.-J.; Chen, J.; Lin, Q.S. Comparison of the sedative and hypnotic effects of flavonoids, saponins, and polysaccharides extracted from Semen Ziziphus jujube. Nat. Prod. Res. 2007, 21, 310-320. [CrossRef]

9. Liu, G.; Liu, X.; Zhang, Y.; Zhang, F.; Wei, T.; Yang, M.; Wang, K.; Wang, Y.; Liu, N.; Cheng, H.; et al. Hepatoprotective effects of polysaccharides extracted from Zizyphus jujube cv. Huanghetanzao. Int. J. Biol. Macromol. 2015, 76, 169-175. [CrossRef]

10. Vafaei, F.; Abdollahzadeh, F. Investigating the effects of hydroalcoholic extract of jujube fruit (Zizyphus vulgaris L.) on second degree burn wound healing in Balb/c mice. J. Med. Life 2015, 8, 117-120.

11. Ghimire, S.; Kim, M.S. Jujube (Ziziphus Jujuba Mill.) fruit feeding extends lifespan and increases tolerance to environmental stresses by regulating aging-associated gene expression in Drosophila. Biogerontology 2017, 18, 263-273. [CrossRef] [PubMed]

12. Rabiei, Z.; Rafieian-Kopaei, M.; Heidarian, E.; Saghaei, E.; Mokhtari, S. Effects of Zizyphus jujube extract on memory and learning impairment induced by bilateral electric lesions of the nucleus Basalis of Meynert in rat. Neurochem. Res. 2014, 39, 353-360. [CrossRef] [PubMed]

13. Park, H.J.; Jung, I.H.; Kwon, H.; Yu, J.; Jo, E.; Kim, H.; Park, S.J.; Lee, Y.C.; Kim, D.H.; Ryu, J.H. The ethanol extract of Zizyphus jujuba var. spinosa seeds ameliorates the memory deficits in Alzheimer's disease model mice. J. Ethnopharmacol. 2019, 233, 73-79. [PubMed]

14. Chen, J.; Lam, C.T.; Li, Z.; Yao, P.; Lin, H.; Dong, T.T.; Tsim, K.W. Extract of Ziziphus jujuba fruit (Jujube) stimulates expression of enzymes responsible for heme recycle via anti-oxidant response element in cultured murine macrophages. Phytother. Res. 2016, 30, 267-271. [CrossRef]

15. Kim, Y.; Oh, J.; Jang, C.H.; Lim, J.S.; Lee, J.S.; Kim, J.S. In vivo anti-inflammatory potential of Viscozyme $\left({ }^{\circledR}\right)$-treated jujube fruit. Foods 2020, 9, 1033. [CrossRef] [PubMed]

16. Mohebbati, R.; Kamkar-Del, Y.; Shafei, M.N. Effect of aqueous and ethyl acetate fractions of Ziziphus jujuba Mill extract on cardiovascular responses in hypertensive rats. Malays. J. Med. Sci. 2020, 27, 43-52. [CrossRef] [PubMed]

17. Kamkar-Del, Y.; Mohebbati, R.; Hosseini, M.; Khajavirad, A.; Shafei, M.N.; Rakhshandeh, H. Ethyl acetate and aqueous fractions of Ziziphus jujuba prevent acute hypertension induced by angiotensin II in Rats. Cardiovasc. Hematol. Disord. Drug Targets 2020, 20, 108-115. [CrossRef]

18. Miao, W.; Sheng, L.; Yang, T.; Wu, G.; Zhang, M.; Sun, J.; Ainiwaer, A. The impact of flavonoids-rich Ziziphus jujuba Mill. extract on Staphylococcus aureus biofilm formation. BMC Complement Med. Ther. 2020, 20, 187. [CrossRef]

19. Arab, M.; Khorashadizadeh, M.; Abotorabi, Z.; Zarban, A. Cytoprotective effects of the aqueous extract of the Ziziphus jujuba fruit on TBHP-induced damage on human fibroblast cells. J. Basic Clin. Physiol. Pharmacol. 2019, 31. [CrossRef]

20. Goswami, P.; Banerjee, R.; Mukherjee, A. potential antigenotoxicity assessment of Ziziphus jujuba fruit. Heliyon 2019, 18, e01768. [CrossRef]

21. Chen, J.; Du, C.Y.Q.; Lam, K.Y.C.; Zhang, W.L.; Lam, C.T.W.; Yan, A.L.; Yao, P.; Lau, D.T.W.; Dong, T.T.X.; Tsim, K.W.K. The standardized extract of Ziziphus jujuba fruit (jujube) regulates pro-inflammatory cytokine expression in cultured murine macrophages: Suppression of lipopolysaccharide-stimulated NF- $\mathrm{kB}$ activity. Phytother. Res. 2014, 28, 1527-1532. [CrossRef] [PubMed]

22. Ebrahimi, S.; Mollaei, H.; Hoshyar, R. Ziziphus Jujube: A review study of its anticancer effects in various tumor models invitro and invivo. Cell Mol. Biol. 2017, 63, 122-127. [CrossRef] [PubMed]

23. Cai, Y.; Zhou, X.; Han, A.; Chen, P.; Bai, H. In vitro immunological and anti-complementary activities of two water-soluble lignins from Zizyphus jujube cv. Jinchangzao. Int. J. Biol. Macromol. 2017, 105, $204-212$. [CrossRef] [PubMed]

24. Jo, S.Y.; Jung, I.H.; Yi, J.H.; Choi, T.J.; Lee, S.; Jung, J.W.; Yun, J.; Lee, Y.C.; Ryu, J.H.; Kim, D.H. Ethanol extract of the seed of Zizyphus jujuba var. spinosa potentiates hippocampal synaptic transmission through mitogen-activated protein kinase, adenylyl cyclase, and protein kinase A pathways. J. Ethnopharmacol. 2017, 200, 16-21. [CrossRef] 
25. Li, L.B.; Kim, Y.W.; Wang, Y.H.; Bai, L.; Zhu, X.D.; Zhao, Z.L.; Lee, C.W.; Jiao, Y.; Wu, T.; Cai, Z.Z.; et al. Methanol extract of semen Ziziphi Spinosae attenuates ethanol withdrawal anxiety by improving neuropeptide signaling in the central amygdala. BMC Complement. Altern. Med. 2019, 19, 147. [CrossRef]

26. Oh, J.M.; Lee, H.S.; Baek, S.C.; Lee, J.P.; Jeong, G.S.; Paik, M.J.; Kim, H. Antidepressant-like activities of hispidol and decursin in mice and analysis of neurotransmitter monoamines. Neurochem. Res. 2020, 45, 1930-1940. [CrossRef]

27. Szewczyk, B.; Pochwat, B.; Muszyńska, B.; Opoka, W.; Krakowska, A.; Rafało-Ulińska, A.; Friedland, K. Antidepressant-like activity of hyperforin and changes in BDNF and zinc levels in mice exposed to chronic unpredictable mild stress. Behav. Brain Res. 2019, 372, 112045. [CrossRef]

28. Porsolt, R.D.; Anton, G.; Blavet, N.; Jalfre, M. Behavioural despair in rats: A new model sensitive to antidepressant treatments. Eur. J. Pharmacol. 1978, 47, 379-391. [CrossRef]

29. Steru, L.; Chermat, R.; Thierry, B.; Simon, P. The tail suspension test: A new method for screening antidepressants in mice. J. Psychopharmacol. 1985, 85, 367-370. [CrossRef]

30. Zheng, M.; Fan, Y.; Shi, D.; Liu, C. Antidepressant-like effect of flavonoids extracted from Apocynum venetum leaves on brain monoamine levels and dopaminergic system. J. Ethnopharmacol. 2013, 147, 108-113. [CrossRef]

31. Baek, S.C.; Park, M.H.; Ryu, H.W.; Lee, J.P.; Kang, M.-G.; Park, D.; Park, C.M.; Oh, S.R.; Kim, H. Rhamnocitrin isolated from Prunus padus var. seoulensis: A potent and selective reversible inhibitor of human monoamine oxidase A. Bioorg. Chem. 2018, 83, 317-325. [PubMed]

32. Lee, J.P.; Kang, M.-G.; Lee, J.Y.; Oh, J.M.; Baek, S.C.; Leem, H.H.; Park, D.; Cho, M.L.; Kim, H. Potent inhibition of acetylcholinesterase by sargachromanol I from Sargassum siliquastrum and by selected natural compounds. Bioorg. Chem. 2019, 89, 103043. [CrossRef] [PubMed]

33. Jeong, J.B.; Shin, Y.K.; Lee, S.H. Anti-inflammatory activity of patchouli alcohol in RAW264.7 and HT-29 cells. Food Chem Toxicol. 2013, 55, 229-233. [CrossRef] [PubMed]

34. Zare-Zardini, H.; Tolueinia, B.; Hashemi, A.; Ebrahimi, L.; Fesahat, F. Antioxidant and cholinesterase inhibitory activity of a new peptide from Ziziphus jujuba fruits. Am. J. Alzheimers Dis. Other Demen. 2013, 28, 702-709. [CrossRef]

35. Kwon, H.; Jung, I.H.; Yi, J.H.; Kim, J.H.; Park, J.H.; Lee, S.; Jung, J.W.; Lee, Y.C.; Ryu, J.H.; Kim, D.H. The seed of Zizyphus jujuba var. spinosa attenuates Alzheimer's disease-associated hippocampal synaptic deficits through BDNF/TrkB signaling. Biol. Pharm. Bull. 2017, 40, 2096-2104. [CrossRef]

36. Kim, H.; Lee, H.E.; Jung, I.H.; Jeon, S.J.; Zhang, J.; Kwon, Y.; Jang, D.S.; Ryu, J.H. The memory ameliorating effects of DHP1402, an herbal mixture, on cholinergic blockade-induced cognitive dysfunction in mice. J. Ethnopharmacol. 2018, 211, 38-46. [CrossRef]

37. Wado, E.K.; Kubicki, M.; Ngatanko, A.H.H.; Blondelle, K.D.L.; Linda, D.J.; Roland, R.N.; Balbine, K.; Lamshoeft, M.; Assongalem, A.E.; Foyet, H.S. Anxiolytic and antidepressant effects of Ziziphus mucronata hydromethanolic extract in male rats exposed to unpredictable chronic mild stress: Possible mechanisms of actions. J. Ethnopharmacol. 2020, 260, 112987. [CrossRef]

38. Lee, Y.; Jeon, S.J.; Lee, H.E.; Jung, I.H.; Jo, Y.W.; Lee, S.; Cheong, J.H.; Jang, D.S.; Ryu, J.H. Spinosin, a C-glycoside flavonoid, enhances cognitive performance and adult hippocampal neurogenesis in mice. Pharmacol. Biochem. Behav. 2016, 145, 9-16. [CrossRef]

39. Zhang, X.; Wang, J.; Gong, G.; Ma, R.; Xu, F.; Yan, T.; Wu, B.; Jia, Y. Spinosin inhibits A $\beta(1-42)$ production and aggregation via activating Nrf2/HO-1 pathway. Biomol. Ther. 2020, 28, 259-266. [CrossRef]

40. Cai, M.; Jung, I.; Kwon, H.; Cho, E.; Jeon, J.; Yun, J.; Lee, Y.C.; Kim, D.H.; Ryu, J.H. Spinosin attenuates Alzheimer's disease-associated synaptic dysfunction via regulation of plasmin activity. Biomol. Ther. 2020, 28, 131-136. [CrossRef]

41. Wang, L.E.; Bai, Y.J.; Shi, X.R.; Cui, X.Y.; Cui, S.Y.; Zhang, F.; Zhang, Q.Y.; Zhao, Y.Y.; Zhang, Y.H. Spinosin, a C-glycoside flavonoid from semen Zizhiphi Spinozae, potentiated pentobarbital-induced sleep via the serotonergic system. Pharmacol. Biochem. Behav. 2008, 90, 399-403. [CrossRef] [PubMed]

42. Xu, F.; Zhang, X.; Wang, J.; Li, X.; He, B.; Xiao, F.; Yan, T.; Wu, B.; Jia, Y.; Wang, Z. Spinosin protects N2a cells from $\mathrm{H}_{2} \mathrm{O}_{2}$-induced neurotoxicity through inactivation of p38MAPK. J. Pharm. Pharmacol. 2020, 72, 1607-1614. [CrossRef] [PubMed] 
43. Gu, M.; He, P.; Lyu, C.; Liu, X.; Xu, Y.; Cheng, S.; Gu, Y.; Jia, Y. Spinosin and $6^{\prime \prime \prime}$-feruloylspinosin protect the heart against acute myocardial ischemia and reperfusion in rats. Mol. Med. Rep. 2019, 20, 4253-4261. [CrossRef]

44. Doron, R.; Versano, Z.; Burstein, O.; Franko, M.; Shamir, A.; Toledano, R.; Handelsman, A.; Rehavi, M. Cerebral MAO activity is not altered by a novel herbal antidepressant treatment. J. Mol. Neurosci. 2019, 69, 371-379. [CrossRef] [PubMed]

45. Willner, P. Validity, reliability and utility of the chronic mild stress model of depression: A 10-year review and evaluation. J. Psychopharmacol. 1997, 134, 319-329. [CrossRef] [PubMed]

46. Willner, P. Chronic mild stress (CMS) revisited: Consistency and behavioural-neurobiological concordance in the effects of CMS. Neuropsychobiology 2005, 52, 90-110. [CrossRef] [PubMed]

47. Lee, S.; Kim, D.H.; Lee, C.H.; Jung, J.W.; Seo, Y.T.; Jang, Y.P.; Ryu, J.H. Antidepressant-like activity of the aqueous extract of allium macrostemon in mice. J. Ethnopharmacol. 2010, 131, 386-395. [CrossRef] [PubMed]

48. Geng, C.A.; Yang, T.H.; Huang, X.Y.; Ma, Y.B.; Zhang, X.M.; Chen, J.J. Antidepressant potential of Uncaria rhynchophylla and its active flavanol, catechin, targeting melatonin receptors. J. Ethnopharmacol. 2019, 232, 39-46. [CrossRef] [PubMed]

49. Cassani, J.; Ferreyra-Cruz, O.A.; Dorantes-Barrón, A.M.; Villaseñor, R.M.; Arrieta-Baez, D.; Estrada-Reyes, R. Antidepressant-like and toxicological effects of a standardized aqueous extract of Chrysactinia mexicana A. Gray (Asteraceae) in mice. J. Ethnopharmacol. 2015, 171, 295-306. [CrossRef]

50. Cryan, J.F.; Mombereau, C.; Vassout, A. The tail suspension test as a model for assessing antidepressant activity: Review of pharmacological and genetic studies in mice. Neurosci. Biobehav. Rev. 2005, 29, 571-625. [CrossRef]

51. Petit-Demouliere, B.; Chenu, F; Bourin, M. Forced swimming test in mice: A review of antidepressant activity. Psychopharmacology. 2005, 177, 245-255. [CrossRef] [PubMed]

52. Björkholm, C.; Monteggia, L.M. BDNF-A key transducer of antidepressant effects. Neuropharmacology 2016, 102, 72-79. [CrossRef] [PubMed]

53. Nibuya, M.; Morinobu, S.; Duman, R.S. Regulation of BDNF and trkB mRNA in rat brain by chronic electroconvulsive seizure and antidepressant drug treatments. J. Neurosci. 1995, 15, 7539-7547. [CrossRef] [PubMed]

54. Wang, Y.L.; Wang, J.X.; Hu, X.X.; Chen, L.; Qiu, Z.K.; Zhao, N.; Yu, Z.D.; Sun, S.Z.; Xu, Y.Y.; Guo, Y.; et al. Antidepressant-like effects of albiflorin extracted from Radix paeoniae Alba. J. Ethnopharmacol. 2016, 179, 9-15. [CrossRef]

55. Mu, R.H.; Fang, X.Y.; Wang, S.S.; Li, C.F.; Chen, S.M.; Chen, X.M.; Liu, Q.; Li, Y.C.; Yi, L.T. Antidepressant-like effects of standardized gypenosides: Involvement of brain-derived neurotrophic factor signaling in hippocampus. J. Psychopharmacol. 2016, 233, 3211-3221. [CrossRef] [PubMed]

56. Lin, Y.E.; Chou, S.T.; Lin, S.H.; Lu, K.H.; Panyod, S.; Lai, Y.S.; Ho, C.T.; Sheen, L.Y. Antidepressant-like effects of water extract of Gastrodia elata Blume on neurotrophic regulation in a chronic social defeat stress model. J. Ethnopharmacol. 2018, 215, 132-139. [CrossRef] [PubMed]

Publisher's Note: MDPI stays neutral with regard to jurisdictional claims in published maps and institutional affiliations.

(C) 2020 by the authors. Licensee MDPI, Basel, Switzerland. This article is an open access article distributed under the terms and conditions of the Creative Commons Attribution (CC BY) license (http://creativecommons.org/licenses/by/4.0/). 